\title{
First Report of Resistance to Quinoxyfen in Podosphaera xanthii, Causal Agent of Cucurbit Powdery Mildew, in the United States
}

M. T. McGrath, Plant Pathology and Plant-Microbe Biology Section, School of Integrative Plant Science, Cornell University, Long Island Horticultural Research and Extension Center, Riverhead, NY, 11901

Accepted for publication 12 April 2017.

Powdery mildew caused by Podosphaera xanthii is a common disease of cucurbit crops occurring worldwide. The most effective management practice is application of fungicides, in particular those with mobility that provide control on the underside of leaves where the pathogen develops best. These tend to be at high risk for resistance development, and $P$. xanthii has proven to be a high risk pathogen for developing resistance (McGrath 2015).

Quintec, which has quinoxyfen (Fungicide Resistance Action Committee Code 13) as the active ingredient, was registered for use in the United States on melons in 2007 and on other nonedible peel cucurbits in 2009. It has been recommended to be used in combination with a multisite fungicide such as chlorothalonil (FRAC Code M5) and in rotation with other effective, targeted fungicides that are also at risk for resistance development: FRAC Code 3 and 7 , plus U6 since 2012 and U8 since 2014.

Fifty-seven isolates of $P$. xanthii were collected in Suffolk Co., New York, at the end of the 2015 growing season for a multiyear project monitoring pathogen sensitivity and resistance to fungicides. Most isolates were from research and commercial field plantings of Halloween pumpkin (Cucurbita pepo). Four were from an organicallymanaged winter squash research planting. Presence of fibrosin bodies in conidia was used to confirm pathogen identity. Isolates were maintained on pumpkin cotyledons with stem end inserted in $0.75 \%$ water agar in petri dishes.

A leaf disk bioassay (Suppl. Fig. S1) was used to determine the ability of isolates to tolerate quinoxyfen and other fungicides. Pumpkin (cv. 'Sorcerer') seedlings at the cotyledon leaf stage (about 7 days old) were sprayed with formulated fungicides in a fume hood, allowed to dry overnight, then disks ( $12 \mathrm{~mm}$ diameter) were cut from cotyledons with a no. 6 core borer and placed on water agar in petri dishes with four sections. Six disks with the same treatment were placed in each section. Each plate used to test an isolate had three treatments plus a nontreated control. Disks were inoculated by transferring a similar amount of spores, based on appearance, from cultures to each disk center using a sterilized, thin, glass rod. Isolate growth was assessed 7 and 10 days later when the control treatment had good growth of the pathogen. An isolate was considered to be insensitive (tolerant) to a particular fungicide concentration if it was able to grow and produce spores on at least half of the disks.

Thirty-eight isolates were tolerant of 200 ppm quinoxyfen, with most not exhibiting reduction in growth relative to the nontreated control disks. They came from two commercial fields and two research plantings where Quintec was used in rotation with other chemistry as recommended for commercial production and from research plots treated with just Quintec or Pristine in a fungicide efficacy experiment (McGrath 2016). An isolate able to tolerate 200 ppm quinoxyfen is not expected to be controlled by Quintec because $212 \mathrm{ppm}$ is the concentration of quinoxyfen when applied at $177 \mathrm{ml} / \mathrm{ha}$ (highest label rate) diluted in water at 468 liters/ha. All quinoxyfen-resistant isolates were resistant to boscalid, the SDHI (FRAC Code 7) ingredient in Pristine, and a subset of isolates tested were resistant to QoI (FRAC Code 11) fungicides and MBC (FRAC Code 1) fungicides. Most quinoxyfen-resistant isolates tolerated 120 or $200 \mathrm{ppm}$ myclobutanil (FRAC Code 3). Occurrence of multifungicide-resistant isolates could account for why quinoxyfen resistance was detected in plots treated with only Pristine but not nontreated plots.

On nearby plants not treated with fungicides at risk for resistance development, sensitive isolates dominated the pathogen population, which suggests selection of resistant isolates occurred during the 2015 season. All eight isolates from nontreated research plots in the fungicide efficacy experiment and all four isolates from an organically managed research planting grew poorly or not at all on $40 \mathrm{ppm}$ quinoxyfen. They were boscalid-sensitive (one was not tested) and three were also QoI-sensitive.

In addition, Quintec and Pristine were as effective as other treatments in the fungicide efficacy experiment, which also suggests selection of the resistant isolates occurred during the 2015 season but not fast enough to affect efficacy.

One of the putative quinoxyfen-resistant isolates from New York was tested and confirmed by Dow AgroScience researchers (A. H. McKay, personal communication). This is the first known occurrence of resistance to quinoxyfen in Podosphaera xanthii in the United States.

\section{Literature Cited}

McGrath, M. T. 2015. Cucurbit powdery mildew in the USA. Pages 401-417 in: Fungicide Resistance in Plant Pathogens: Principles and a Guide to Practical Management. H. Ishii and D. W. Hollomon. Springer, Tokyo, Japan.

McGrath, M. T. 2016. Efficacy of fungicides for managing powdery mildew in pumpkin, 2015. Plant Dis Managem. Rep. 10:V040. 